\title{
Outcomes of Intrathecal Baclofen Therapy Compared With Deep Brain Stimulation in a Patient With Dystonic Cerebral Palsy: A Case Report
}

\author{
Minji Chae, $\mathrm{MD}^{1}$, Seungbeen Hong, $\mathrm{MD}^{1}$, Na Young Jung, $\mathrm{MD}^{2,3}$, \\ Won Seok Chang, MD, $\mathrm{PhD}^{2}$, Sung-Rae Cho, $\mathrm{MD}, \mathrm{PhD}^{1,4}$
}

\begin{abstract}
${ }^{1}$ Department of Rehabilitation Medicine and Research Institute of Rehabilitation Medicine, Yonsei University College of Medicine, Seoul; ${ }^{2}$ Department of Neurosurgery and Brain Research Institute, Yonsei University College of Medicine, Seoul; ${ }^{3}$ Department of Neurosurgery, Ulsan University Hospital, University of Ulsan College of Medicine, Ulsan; ${ }^{4}$ Brain Korea 21 PLUS Project for Medical Science, Yonsei University, Seoul, Korea
\end{abstract}

Deep brain stimulation (DBS) in internal globus pallidus is considered to be a good option for controlling generalized dystonia in patients with this condition. In this relation, it is known that DBS has already been shown to have significant effects on primary dystonia, but is seen as controversial in secondary dystonia including cerebral palsy (CP). On the other hand, intrathecal baclofen (ITB) has been known to reduce spasticity and dystonia in patients who did not respond to oral medications or botulinum toxin treatment. Here, we report a patient with dystonic $\mathrm{CP}$, who received the ITB pump implantation long after the DBS and who noted remarkable improvement in the 36-Item Short Form Health Survey, Dystonia Rating Scale, Modified Barthel Index, and visual analog scale scores for pain after an ITB pump implantation was used as compared with DBS. To our knowledge, the present case report is the first to demonstrate the effects of an ITB pump on reducing pain and dystonia and improving quality of life and satisfaction, compared with DBS in a patient with CP.

Keywords Dystonia, Intrathecal baclofen pump, Deep brain stimulation, Cerebral palsy

\section{INTRODUCTION}

Cerebral palsy $(\mathrm{CP})$ is a group of non-progressive dis- orders characterized with an abnormal control of movement and posture, and it is diagnosed most frequently in early childhood. Adults with CP often suffer from move-

\footnotetext{
Received August 23, 2018; Accepted October 1, 2018

Corresponding author: Sung-Rae Cho

Department of Rehabilitation Medicine, Yonsei University College of Medicine, 50-1 Yonsei-ro, Seodamun-gu, Seoul 03722, Korea. Tel: +82-2-22283715, Fax: +82-2-363-2795, E-mail: srcho918@yuhs.ac

ORCID: Minji Chae (http://orcid.org/0000-0002-0590-2113); Seungbeen Hong (http://orcid.org/0000-0002-8222-2920); Na Young Jung (http://orcid. org/0000-0001-9996-1378); Won Seok Chang (http://orcid.org/0000-0003-3145-4016); Sung-Rae Cho (http://orcid.org/0000-0003-1429-2684).
}

(c) This is an open-access article distributed under the terms of the Creative Commons Attribution Non-Commercial License (http://creativecommons.org/ licenses/by-nc/4.0) which permits unrestricted noncommercial use, distribution, and reproduction in any medium, provided the original work is properly cited. Copyright (C) 2019 by Korean Academy of Rehabilitation Medicine 
ment disorders and postural problems due to involuntary muscle contractions. Although $\mathrm{CP}$ is not a progressive disorder, movement symptoms such as spasticity, dyskinesia, and dystonia cause chronic pain, affect functional level, and can significantly degrade the patient's quality of life.

As has been seen, dystonia is often found in CP mixed with spasticity, where it is referred to as 'mixed' tone. Damage of the extrapyramidal system, which occurs by hypoxic brain damage or kernicterus, can cause dystonia in some affected CP patients. To this end, dystonic CP patients frequently have musculoskeletal deformity and pain over time due to spasticity and dystonia. There are several types of treatment for dystonic movement in CP patients such as oral medications, botulinum toxin treatment, intrathecal baclofen (ITB) treatment, and deep brain stimulation (DBS). However, there is currently a lack of consensus regarding the better approach for the treatment and pain management going forward in $\mathrm{CP}$ patients with severe dystonia.

It is noted that in this context, DBS in the internal globus pallidus ( $\mathrm{GPi}$ ) has been known as a good treatment option for controlling generalized dystonia. Although DBS has a significant effect on primary dystonia, it is controversial on noting a patient's secondary dystonia including CP [1]. On the other hand, an ITB treatment has been known as a treatment to reduce spasticity that is not effective in the case of using oral medications or botulinum toxin treatment. Many studies of ITB treatment have also reported significant decreases in dystonia as seen in some affected patients $[2,3]$.

Here, we report a patient with dystonic CP, who received the ITB treatment long after the DBS. This patient did not respond to oral medications and botulinum toxin treatment and was treated initially with DBS and subsequently with ITB therapy. The present case report is the first to demonstrate the effects of ITB treatment on reducing pain and dystonia and improving the patient's quality of life and satisfaction as compared with DBS in a patient with dystonic CP.

\section{CASE REPORT}

A 35-year-old female patient visited to the department of rehabilitation medicine presenting with posterior neck pain and right upper extremity pain combined with se- vere dystonia. Upon a review of the patient's medical history, it is noted that she was diagnosed with $\mathrm{CP}$ at the age of one. She has experienced severe dystonia especially in her neck and both upper extremities; Dystonia Rating Scale (DRS) score was 66 points on the dystonia movement scale and 19 points on the disability scale. Spasticity was identified as grade 2 in the right upper extremity, grade $1+$ in left upper extremity, and grade 1 in both lower extremities on the Modified Ashworth Scale (MAS). The patient had noted a measurement of 53 points on the Modified Barthel Index (MBI). She also suffered from pain in her posterior neck and both shoulders with a visual analog scale (VAS) score of 8. Although she had been treated previously with oral medication and botulinum toxin injection, those treatments resulted in no reduction in the severity of the patient's pain and dystonia.

To exclude whether she had genetic primary dystonia, a fragment analysis was performed on the DYT1 gene, and the GAG deletion was not observed at that time. There were no corroborating symptoms and no abnormal results in blood tests and urinalyses to indicate the presence of Wilson's disease in the patient. Additionally, the brain magnetic resonance imaging showed no notable findings, but it is noted that fluorodeoxyglucose uptake in a positron emission tomography was slightly decreased in the right hemisphere.

This patient received DBS in the consultation with the neurosurgeons. The target position of DBS electrode implantation on both GPi was confirmed through plain skull X-ray and brain computed tomography scan after surgery (Fig. 1). In this case, the therapeutic outcomes were assessed as DRS, MBI, 36-Item Short Form Health Survey (SF-36), and VAS scores after receiving DBS on the GPi. On the dystonia movement scale of the DRS, the patient scored 66 before DBS, but 3, 6, and 12 months later, she scored 72 . Six years later, the patient scored 75 , which was worse than her pre-DBS state. On the disability scale of the DRS, it is noted that the patient scored 19 before DBS, 27 one year after DBS, and 22 six years after DBS (Table 1). In activities in daily living (ADL), the patient's MBI score gradually decreased and she showed persistent deterioration in functional level after DBS (Table 2). In spasticity, the right upper extremity was scored a grade 3 , the left upper extremity scored a grade 3 , and both the lower extremities a grade 1+ on the MAS, all of which was an increase over the pre-DBS state. 

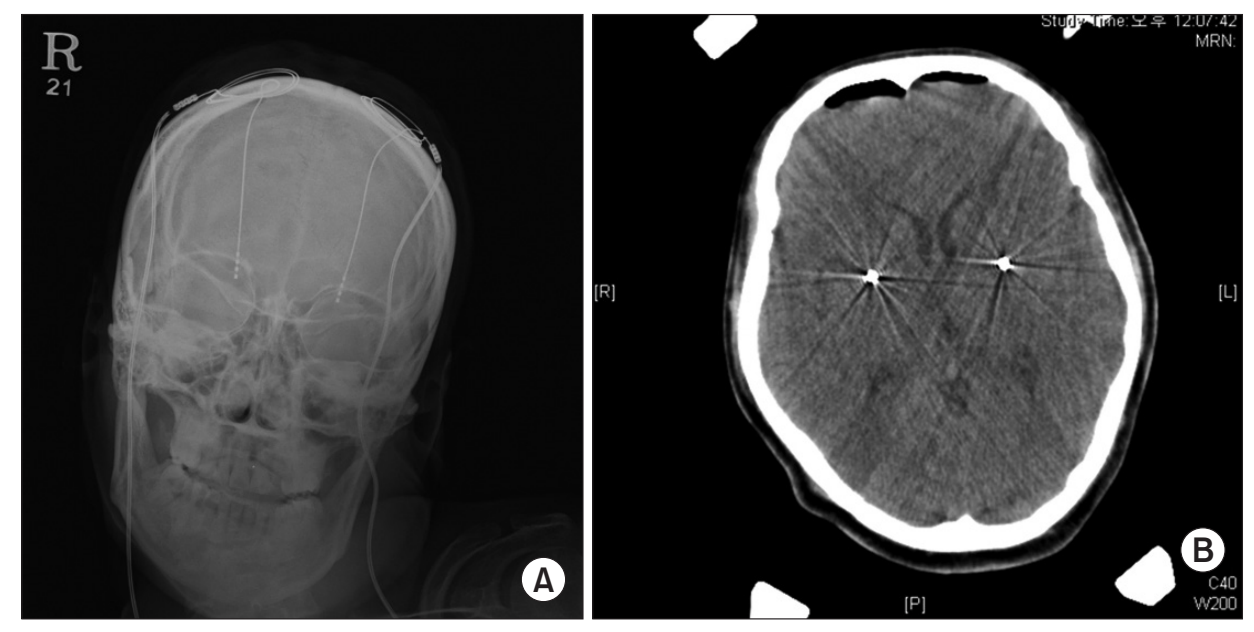

Fig. 1. Plain skull X-ray (A) and brain computed tomography scan (B) showing a deep brain stimulation electrode located on the internal globus pallidus bilaterally.

Table 1. Changes in dystonia rating scale score after DBS and ITBP

\begin{tabular}{|c|c|c|c|c|c|c|c|c|c|c|c|}
\hline \multirow{2}{*}{$\begin{array}{c}\text { Dystonia rating } \\
\text { scale }\end{array}$} & \multirow{2}{*}{$\begin{array}{l}\text { Pre- } \\
\text { DBS }\end{array}$} & \multicolumn{5}{|c|}{ Post-DBS } & \multirow{2}{*}{$\begin{array}{c}\text { ITB test } \\
\text { trial }\end{array}$} & \multicolumn{4}{|c|}{ Post-ITBP } \\
\hline & & $3 \mathrm{mo}$ & $6 \mathrm{mo}$ & $12 \mathrm{mo}$ & $24 \mathrm{mo}$ & $72 \mathrm{mo}$ & & $3 \mathrm{mo}$ & $6 \mathrm{mo}$ & $12 \mathrm{mo}$ & $24 \mathrm{mo}$ \\
\hline $\begin{array}{l}\text { Dystonia movement } \\
\text { scale }\end{array}$ & 66 & 72 & 72 & 72 & 70 & 75 & 64.5 & 63 & 63 & 65 & 64 \\
\hline Disability scale & 19 & 20 & 26 & 27 & 25 & 22 & 23 & 23 & 21 & 19 & 20 \\
\hline
\end{tabular}

DBS, deep brain stimulation; ITB, intrathecal baclofen; ITBP, intrathecal baclofen pump implantation.

Table 2. Changes in the MBI score after DBS and ITBP

\begin{tabular}{|c|c|c|c|c|c|c|c|}
\hline \multirow{2}{*}{ MBI } & \multirow{2}{*}{ Pre-DBS } & \multicolumn{2}{|c|}{ Post-DBS } & \multirow{2}{*}{$\begin{array}{c}\text { ITB } \\
\text { test trial }\end{array}$} & \multicolumn{3}{|c|}{ Post-ITBP } \\
\hline & & $6 \mathrm{mo}$ & $72 \mathrm{mo}$ & & $6 \mathrm{mo}$ & $12 \mathrm{mo}$ & $24 \mathrm{mo}$ \\
\hline Personal hygiene & 0 & 0 & 0 & 0 & 0 & 0 & 0 \\
\hline Bathing self & 0 & 0 & 0 & 0 & 0 & 0 & 0 \\
\hline Feeding & 0 & 0 & 0 & 5 & 2 & 2 & 2 \\
\hline Toilet & 0 & 0 & 0 & 2 & 2 & 2 & 2 \\
\hline Stair climbing & 10 & 0 & 0 & 8 & 8 & 5 & 5 \\
\hline Dressing & 2 & 2 & 0 & 0 & 2 & 2 & 2 \\
\hline Bowel control & 8 & 8 & 8 & 8 & 8 & 8 & 8 \\
\hline Bladder control & 8 & 8 & 8 & 8 & 8 & 8 & 8 \\
\hline Ambulation & 15 & 8 & 3 & 12 & 12 & 12 & 12 \\
\hline Chair/bed transfer & 12 & 8 & 8 & 12 & 12 & 12 & 12 \\
\hline Total & 53 & 34 & 27 & 55 & 54 & 51 & 51 \\
\hline
\end{tabular}

MBI, Modified Barthel Index; DBS, deep brain stimulation; ITB, intrathecal baclofen; ITBP, intrathecal baclofen pump implantation.

Seven years after the DBS, the patient was given a $50-\mu \mathrm{g}$ ITB bolus injection to assess the response to treatment and the presence of adverse events. Broadly speaking, the patient's dystonia movement scale and pain in the posterior neck and both shoulders were all markedly reduced after treatment with ITB (Table 1). Likewise, after a $75-\mu \mathrm{g}$
ITB bolus injection to further evaluate functional change, the patient could not stand without assistance due to excessively reduced muscle tone in her lower extremities. Later, an ITB catheter infusion test trial was performed to decide ITB pump implantation, which was effective in reducing spasticity, pain, and dystonia in the patient. There 
was also remarkable improvement in the MBI score without excessive reduction of muscle tone in the patient's lower extremities (Table 2).

An ITB pump implantation was performed in this patient who showed a definitive positive response to the ITB test trials and also experienced no adverse events. To further control the spasticity of her upper extremity, an intrathecal catheter tip was applied up to the level of T5. After the procedure of the pump implantation, the patient was started at a dose of $50 \mu \mathrm{g}$ ITB, which was gradually increased to $130 \mu \mathrm{g}$. On the dystonia movement scale, the patient scored 72 before ITB pump implantation, but 3 months later, she scored 63 . Two years later, it is noted that the patient scored 64, which demonstrates a marked reduction of dystonia. On the disability scale, the patient scored 22 before the ITB pump implantation, but 2 years later, she scored 20 , which represented a mild reduction of disability (Table 1). The patient's ADL score was also improved in the MBI after the ITB pump implantation compared to pre-ITB state (Table 2). In particular, although it was recorded that the patient had severe pain in her posterior neck and shoulders with a VAS score of 8 before the ITB pump implantation, the pain decreased to VAS score of 1 after the pump implantation (Table 3). It

Table 3. Comparison of the patient's responses to DBS and ITBP

\begin{tabular}{|ccc}
\hline & Post-DBS & Post-ITBP \\
\hline Pain (VAS) & 8 & 1 \\
\hline $\begin{array}{l}\text { SF-36 } \\
\quad \text { Physical functioning }\end{array}$ & 0 & 50 \\
\hline $\begin{array}{l}\text { Role limitations due to } \\
\text { physical health }\end{array}$ & 0 & 75 \\
$\quad$ Bodily pain & 22.5 & 67.5 \\
\hline General health & 60 & 70 \\
\hline Vitality & 12.5 & 62.5 \\
\hline Social functioning & 25 & 100 \\
\hline $\begin{array}{l}\text { Role limitations due to } \\
\text { emotional problems }\end{array}$ & 0 & 100 \\
\hline Emotional well being & 15 & 75 \\
\hline Physical component score & 20.63 & 65.63 \\
\hline Mental component score & 13.13 & 84.38 \\
\hline
\end{tabular}

DBS, deep brain stimulation; ITBP, intrathecal baclofen pump implantation; VAS, visual analog scale; SF-36, Short Form 36 Health Survey version 2. is noted that the post-ITB pump satisfaction scores were remarkably higher as compared to the post-DBS satisfaction scores for all items of the SF-36 (Table 3).

\section{DISCUSSION}

Management of dystonia in CP is important because dystonia can impair motor function, cause pain, and reduce independency of daily activities in the patients affected with this condition. Dystonia is classified as primary dystonia, which is caused by hereditary or unknown factors, and secondary dystonia, which can be caused by brain injury or Wilson's disease. For primary dystonia, DBS in the GPi is known to be an effective treatment. However, DBS appears to be not so effective for the treatment of secondary dystonia in most cases [1]. When this patient received DBS, the ITB treatment was not universal because it was not covered as a qualified condition reimbursed by the patient's applicable National Health Insurance Service, South Korea. Based on a previous study [4] which reported a therapeutic effect of bilateral pallidal DBS on CP patients with dystonia-choreoathetosis, we tried a DBS treatment in this patient with dystonic CP. However, the DRS and MBI scores showed a deterioration after DBS in this patient, although there were no other factors that were known that would worsen this patient's functional status. Even if the exact mechanism has not been yet elucidated, our previous experience [5] demonstrated that the disability scale was not changed or functionally aggravated after DBS in CP patients with dystonia, whereas the DRS dramatically improved after DBS in primary dystonia. Andrews et al. [6] also suggested the existence of an incident of irreversible anatomical lesions in patients with secondary dystonia, which may lower the response to DBS. Therefore, an ITB trial should be considered in patients with $\mathrm{CP}$ who did not respond to oral medications or botulinum toxin injection rather than the utilization of a DBS treatment when severe spasticity and secondary dystonia coexist in the patient's condition.

Narayan et al. [7] first introduced the beneficial use of a continuous infusion of ITB for intractable axial dystonia treatment. The mechanism of baclofen in treating dystonia remains unclear, although it is seen that this drug may act both on spinal cord level and cortical level. In general, baclofen, a gamma-aminobutyric acid (GABA) agonist, selectively acts on GABA-B receptors in the brain 
and the dorsal grey matter of the spinal cord. Then, it is noted that the calcium influx is restricted to the presynaptic terminal, which inhibits the secretion of presynaptic neurotransmitter. It also affects the postsynaptic terminal by the decreasing neuronal activity by increasing the potassium flow [8]. In the model of a basal ganglia function developed by Alexander and Crutcher [9], motor output was found to be modulated by a cortico-basal gangliathalamocortical circuit, which contains a direct and an indirect pathway. Direct pathway lesions typically lead to hypokinetic movement disorders such as Parkinsonism, and it is known that indirect pathway lesions lead to hyperkinetic movement disorders such as dystonia. In this respect, it is known that CP patients with secondary dystonia often have lesions in the striatum, primarily in the putamen. The putamen forms numerous connections with external globus pallidus (GPe) and the subthalamic nucleus. Of those, it is shown that the GABAergic projections of the putamen have an inhibitory effect on the subthalamic nucleus. Damage to this inhibitory pathway, such as a perinatal insult to the putamen, can result in an excessive output from the subthalamic nucleus leading to an abnormal increase in involuntary motor movements or hyperkinesia. In order to inhibit the overly stimulated motor output, a continuous infusion of ITB targets the GABAergic projections in the basal ganglia. In addition, the position of the ITB catheter tip can affect the resulting dystonia control [10]. In this case, the ITB catheter was placed at the level of T5, and this placement resulted in a high efficacy of ITB for generalized dystonia and spasticity in the patient's neck and upper extremities.

This patient showed improvement in pain, dystonia, and functional level after the use of the ITB pump implantation as compared with DBS. Namely, it is noted that the ITB treatment improved the scores as compared to the pre-ITB treatment state (post-DBS 72 months). Since the patient showed mild impairment in a stair climbing item of the MBI due to reduced muscle tone in her lower extremities, we gradually decreased the ITB infusion dose from $140 \mu \mathrm{g}$ to $115 \mu \mathrm{g}$ through the time of the regular follow-up in outpatient clinics.

We hypothesize that there may be two important reasons why ITB therapy was more effective for this patient as compared with DBS. First, this patient showed dystonia and spasticity concurrently, which represents a mixed type of condition result. Second, the noted dystonic movement in this CP patient who had a functional or structural encephalopathy resulting from developmental abnormalities is classified as a secondary dystonia. Therefore, DBS may not be effective in these patients for the reason that the brain circuitry is not intact. In case a DBS treatment shows no effect or functional deterioration in patients with secondary dystonia such as $\mathrm{CP}$, an ITB treatment can be considered for the treatment of dystonia.

In conclusion, we report a patient with dystonic $\mathrm{CP}$, who received the ITB pump implantation long after the DBS, who did not respond to a course of oral medications and botulinum toxin treatment, and who was treated initially with DBS and subsequently with ITB therapy. The ITB therapy resulted in a remarkable improvement of dystonia, functional level, pain, and satisfaction in the overall health status as compared with DBS in a patient with dystonic $\mathrm{CP}$ mixed with spasticity.

\section{CONFLICT OF INTEREST}

No potential conflict of interest relevant to this article was reported.

\section{AUTHOR CONTRIBUTION}

Conceptualization: Cho SR, Chae M. Methodology: Cho SR, Chang WS, Jung NY. Formal analysis: Chae M, Hong S. Project administration: Cho SR, Chae M. Visualization: Chae M, Hong S. Writing - original draft: Chae M. Writing - review and editing: Cho SR, Chae M, Hong S. Approval of final manuscript: all authors.

\section{REFERENCES}

1. Kupsch A, Benecke R, Muller J, Trottenberg T, Schneider GH, Poewe W, et al. Pallidal deep-brain stimulation in primary generalized or segmental dystonia. N Engl J Med 2006;355:1978-90.

2. Yoon YK, Lee KC, Cho HE, Chae M, Chang JW, Chang WS, et al. Outcomes of intrathecal baclofen therapy in patients with cerebral palsy and acquired brain injury. Medicine (Baltimore) 2017;96:e7472.

3. Eek MN, Olsson K, Lindh K, Askljung B, Pahlman M, Corneliusson $\mathrm{O}$, et al. Intrathecal baclofen in dyskinetic cerebral palsy: effects on function and activity. 
Dev Med Child Neurol 2018;60:94-9.

4. Vidailhet M, Yelnik J, Lagrange C, Fraix V, Grabli D, Thobois S, et al. Bilateral pallidal deep brain stimulation for the treatment of patients with dystonia-choreoathetosis cerebral palsy: a prospective pilot study. Lancet Neurol 2009;8:709-17.

5. Kim AR, Chang JW, Chang WS, Park ES, Cho SR. Twoyear outcomes of deep brain stimulation in adults with cerebral palsy. Ann Rehabil Med 2014;38:209-17.

6. Andrews C, Aviles-Olmos I, Hariz M, Foltynie T. Which patients with dystonia benefit from deep brain stimulation? A metaregression of individual patient outcomes. J Neurol Neurosurg Psychiatry 2010;81:1383-9.
7. Narayan RK, Loubser PG, Jankovic J, Donovan WH, Bontke CF. Intrathecal baclofen for intractable axial dystonia. Neurology 1991;41:1141-2.

8. Zieglgansberger W. Dorsal horn neuropharmacology: baclofen and morphine. Ann N Y Acad Sci 1988; 531:150-6.

9. Alexander GE, Crutcher MD. Functional architecture of basal ganglia circuits: neural substrates of parallel processing. Trends Neurosci 1990;13:266-71.

10. Albright AL, Barry MJ, Shafton DH, Ferson SS. Intrathecal baclofen for generalized dystonia. Dev Med Child Neurol 2001;43:652-7. 